\title{
A Numerical Study on the Supersonic Steam Ejector Use in Steam Turbine System
}

\author{
Lin Cai and Miao He \\ China Ship Development and Design Center, Wuhan, Hubei 433064, China \\ Correspondence should be addressed to Lin Cai; cailin03313@163.com
}

Received 11 October 2012; Revised 22 November 2012; Accepted 6 December 2012

Academic Editor: Zhijun Zhang

Copyright ( 2013 L. Cai and M. He. This is an open access article distributed under the Creative Commons Attribution License, which permits unrestricted use, distribution, and reproduction in any medium, provided the original work is properly cited.

\begin{abstract}
Supersonic steam ejector is widely used in steam energy systems such as refrigeration, wood drying equipment, papermaking machine, and steam turbine. In this paper the Computational Fluids Dynamics (CFD) method was employed to simulate a supersonic steam ejector, SST k-w turbulence model was adopted, and both real gas model and ideal gas model for fluid property were considered and compared. The mixing chamber angle, throat length, and nozzle exit position (NXP) primary pressure and temperature effects on entrainment ratio were investigated. The results show that performance of the ejector is underestimated using ideal gas model, and the entrainment ratio is $20 \%-40 \%$ lower than that when using real gas model. There is an optimum mixing chamber angel and NXP makes the entrainment ratio achieve its maximum; as throat length is decreased within a range, the entrainment ratio remains unchanged. Primary fluid pressure has a critical value, and the entrainment ratio reaches its peak at working critical pressure; when working steam superheat degree increases, the entrainment ratio is increased.
\end{abstract}

\section{Introduction}

The supersonic steam ejector (SSE) is widely used in many industry fields which are steam powered such as oil, thermoelectric, and refrigeration [1-3]. A steam jet refrigeration can be considered as one of the most suitable refrigeration systems for the present energy and environment situations, because of simple mode of function, lack of moving parts, and capability of driving a refrigeration device primarily through the use of waste heat or solar energy making them particularly attractive in this energy-conscious era. In addition, using waste heat or solar energy to power a refrigeration system will reduce the electrical energy consumption used to power vapour-compression refrigeration systems, potentially reducing the emissions of greenhouse gasses that are associated with the production of electricity from fossil fuel burning power plants. In view of the numerous publications available on this subject, it is perhaps one of the most important application areas for ejectors. A good overview of the different applications in this field may be found in the review article by Sun and Eames (1995) [4]. So a lot of studies of SSE performance with various types of working fluid in refrigeration field could be found; for example, Eames et al. [5] provided the results of $1 \mathrm{D}$ model theoretical and experimental study of a steam jet refrigerator. Huang [6] carried out a 1D model on ejector performance at critical-mode operation; Ouzzane and Aidoun (2003) [7] proposed a 1D model allowing to track flow conditions along the ejector. In their study, fluid properties were evaluated by using NIST (1980) subroutines for equations of state of refrigerants. CFD tools have been proved to be valuable tools for understanding and solving complex fluid flow problems, such as the entrainment and mixing processes in ejectors. Bartosiewicz et al. [8] compared the pressure distribution by using different turbulence models for the simulation of an ejector with experimental data. It was concluded that, for certain conditions, simulated results were in excellent agreement with measured data. However, the choice of air as a working fluid and other test conditions was not very fortunate, especially when a cooling cycle is concerned. Later they extended their work using R142b as the working fluid. Rusly et al. [9] presented CFD results compared to published experimental data and 1D model predictions, using R141b. The effect of ejector geometry on the flow field was investigated. It was pointed out that according 
TABLE 1: Summary of ejector research using CFD software compared with experimental results.

\begin{tabular}{|c|c|c|c|c|c|}
\hline Auto & Working fluids & State equation & Numerical method & $\begin{array}{l}\text { Inlet pressure } \\
\text { (range) }\end{array}$ & Error range \\
\hline Eames et al. [5] & Water steam & Ideal gas model & 1D model & $0.3615 \mathrm{MPa}$ & $22.6 \sim 32.25 \%$ \\
\hline Huang et al. [6] & $\mathrm{R} 141 \mathrm{~b}$ & Ideal gas model & 1D model & $0.4-0.6 \mathrm{MPa}$ & $0.56 \sim 22.9 \%$ \\
\hline Rusly et al. [9] & R141b & Ideal gas model & FLUENT & $0.4-0.6 \mathrm{MPa}$ & $-5.82 \sim 5.11 \%$ \\
\hline $\begin{array}{l}\text { Pietrowicz and } \\
\text { Kasperski [10] }\end{array}$ & Water steam & IAPWS-IF97 & CFX & $0.474 \mathrm{KPa}$ & $1.3 \sim 8.2 \%$ \\
\hline Sriveerakul et al. [11] & Water steam & Ideal gas model & FLUENT & $0.27 \mathrm{Mpa}$ & $-1.89 \sim 12.9 \%$ \\
\hline Pianthong et al. [12] & Water steam & Ideal gas model & FLUENT & $0.3615 \mathrm{MPa}$ & $1 \% \sim 13.4 \%$ \\
\hline Scott et al. [13] & $\mathrm{R} 245 \mathrm{fa}$ & NIST & PHOENICS & $0.4-0.6 \mathrm{MPa}$ & $-4.9 \sim 10.6 \%$ \\
\hline
\end{tabular}

to CFD model results, $1 \mathrm{D}$ model assumptions were not met under test conditions. In this work, evaporator temperatures were very high for a simple ejector cooling cycle. T. Pietrowicz and Kasperski [10] used a commercial CFD package to predict performance of a steam ejector, and the maximum errors of many different working conditions such as effect of primary nozzle, throat diameter, and throat length are $12.9 \%$. A pithy review is listed in Table 1.

In this paper, the SSE used in steam turbine system has been calculated using CFD package CFX 11.0; applying the SSE to steam turbine system could hold the vacuum; it could also pump the noncondensable gas and enhance the efficiency of Rankine cycle indirectly [3]. According to the review of ejector studies above, it could be found that the ejector working pressure is less than $1 \mathrm{MPa}$; water vapour, used as the working fluid of the model, was treated as the assumption of an ideal gas, for the ejector application where the operating pressure is relatively low; it was proved by some researchers [10] that it provided similar results to a real gas model, but the SSE investigated in this paper is working at $1.6 \mathrm{MPa}$ or even higher, so the ideal gas model does not apply at all to water vapour; on the other hand, it can be found from Table 1 that, in the literature review, the CFD and experiment works of SSE primary pressure are almost lower than $1 \mathrm{MPa}$, so the SSE working at a higher primary pressure should be investigated in order to learn the performance of the SSE used in steam turbine system and provide some theoretical foundations for designing the SSE with high primary pressure. The previous part of this paper, both Laval nozzle and ejector results of different equations of state have been compared; then the geometry and operation condition effects on SSE entrainment ratio (EM = mass flow rate of secondary inlet/mass flow rate of primary inlet) are discussed. This paper could provide the theory basis for the high primary SSE design.

\section{Ejector Geometry}

The ejector simulated in this paper is shown in Figure 1 and the original geometry detail is shown in Table 2 . The mixing chamber angle $\alpha$, throat length $L$, and nozzle exit position (NXP) effects on ejector entrainment ratio have been considered, $\alpha$ is changed from $4.5^{\circ}$ to $13.25^{\circ}$, which means that the mixing chamber length is changed from $75 \mathrm{~mm}$ to
$225 \mathrm{~mm}$, and the throat length is changed from $2 \mathrm{D}$ to $6 \mathrm{D}$. When considering one parameter effect, the other remains unchanged at original or optimal value.

\section{CFD Model}

The calculation area is meshed with structural mesh hexahedral-type elements using ICEM 11.0 (Figure 2); 1/4 model is considered for saving calculation time; if the apex angle between two symmetry faces is small, the mesh quality becomes very poor, so a $1 / 4$ geometry model with apex angle $90^{\circ}$ was used. CFD software CFX 11.0 is used to solve the governing equations. The pressure inlet type is taken into primary and secondary inlet, for primary inlets; the total pressure $1.6 \mathrm{MPa}$ and total temperature $556.85 \mathrm{~K}$ are given; for secondary inlet, the total pressure $0.01 \mathrm{MPa}$ and total temperature $315 \mathrm{~K}$ are given. The pressure outlet boundary with a known mean value of absolute pressure at $33170 \mathrm{~Pa}$ is adopted for ejector outlet. No-slip and adiabatic wall type have been used on the ejector wall. Automatic near-wall treatment has been applied. The SST k-w model is utilized for simulating turbulence flow.

The gird-dependent learning is done using $d=40 \mathrm{~mm}$ geometry as shown in Table 1, and four options are considered as shown in Table 3; it can be seen that the entrainment ratio is changed within $3.88 \%$; the scheme 3 is used in this paper.

The fluid property is important for simulation steam flow problem, especially when the steam is far away from critical region, so the IAPWS IF97 model is used as equation of state. The IAPWS-IF97 database represents an accurate equation of state for water and steam properties. The IAPWS-IF97 [15] database uses formulations for five distinct thermodynamic regions (Figure 3) for water and steam, namely, (1) subcooled water, (2) supercritical water/steam, (3) superheated steam, (4) saturation data, and (5) high temperature steam. When developing the IAPWS database for ANSYS CFX, therefore, properties must be evaluated as functions of pressure and temperature. For the most part, this involves a straightforward implementation of the equations described in the IAPWS theory. Region 4 involves saturation data that uses only pressure or temperature information. However, when evaluating the properties around Region 3 (near the critical point), where the EOS is defined explicitly in terms of density and temperature. In this region, the density must be 


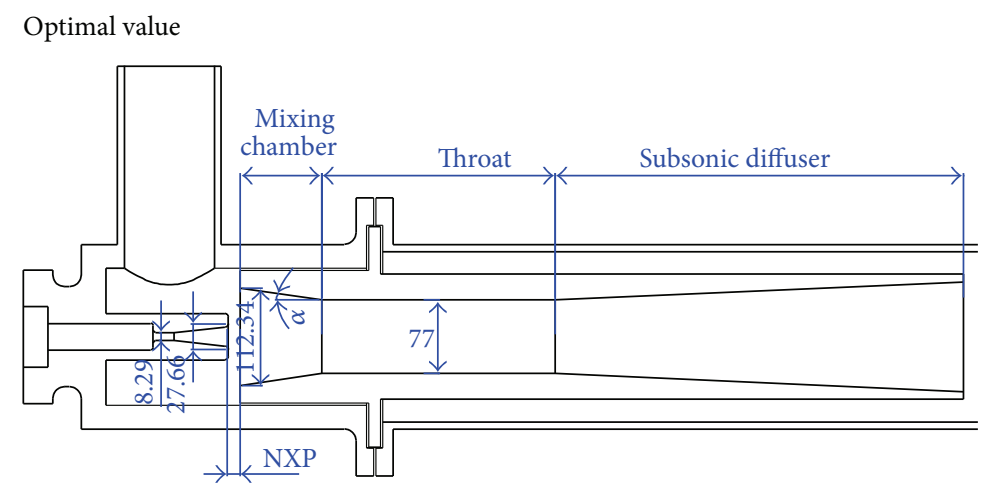

FIGURE 1: Schematic diagram of steam ejector (not in scale).

TABLE 2: The original geometry details of the ejector.

\begin{tabular}{lcc}
\hline Mixing chamber angle & $\alpha\left(^{\circ}\right)$ & 9.55 \\
Throat length & $L(\mathrm{~mm})$ & 485 \\
Diffuser length & $L_{d}(\mathrm{~mm})$ & 305 \\
Diameter of throat & $D_{t}(\mathrm{~mm})$ & 77 \\
$\begin{array}{l}\text { Diameter of diffuser outlet } \\
\text { Distance between primary nozzle }\end{array}$ & $D_{d}(\mathrm{~mm})$ & 141.5 \\
and mixing chamber & $d(\mathrm{~mm})$ & 10 \\
\hline
\end{tabular}

TABLE 3: Grid-dependent results.

\begin{tabular}{lcccc}
\hline Scheme & Total elements & $L$ & $L_{d}$ & $E_{m}$ \\
\hline 1 & 124136 & 63 & 51 & 0.670 \\
2 & 332668 & 90 & 72 & 0.691 \\
3 & 519486 & 104 & 84 & 0.693 \\
4 & 608685 & 155 & 94 & 0.697 \\
\hline
\end{tabular}

evaluated using Newton-Raphson iteration. This algorithm is further complicated in that the EOS is applicable on both the subcooled liquid and superheated vapor side leading up to critical conditions. Therefore, depending on the pressuretemperature state, one may be evaluating a subcooled liquid or a superheated vapor with the same EOS. To apply the Newton-Raphson scheme in a reliable way, one must detect on which side of the saturation dome the pressuretemperature state applies, and apply an appropriate initial guess. Such an iteration scheme, including logic for an initial guess, has been implemented in ANSYS CFX so that table generation around the critical region is possible.

\section{Numerical Results}

4.1. Numerical Validation. In order to verify the reliability of the theoretical model, a converging-diverging nozzle flow field has been calculated. The geometry and inlet conditions of the nozzle were taken to be the same as the Nozzle B used in the experiment of Moore and Walters (1973) [14], which was

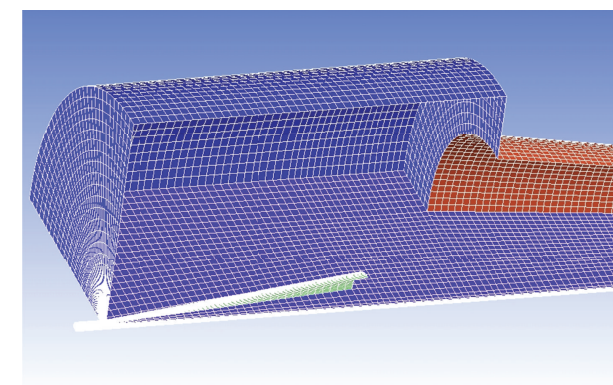

Figure 2: Mesh of flow region.

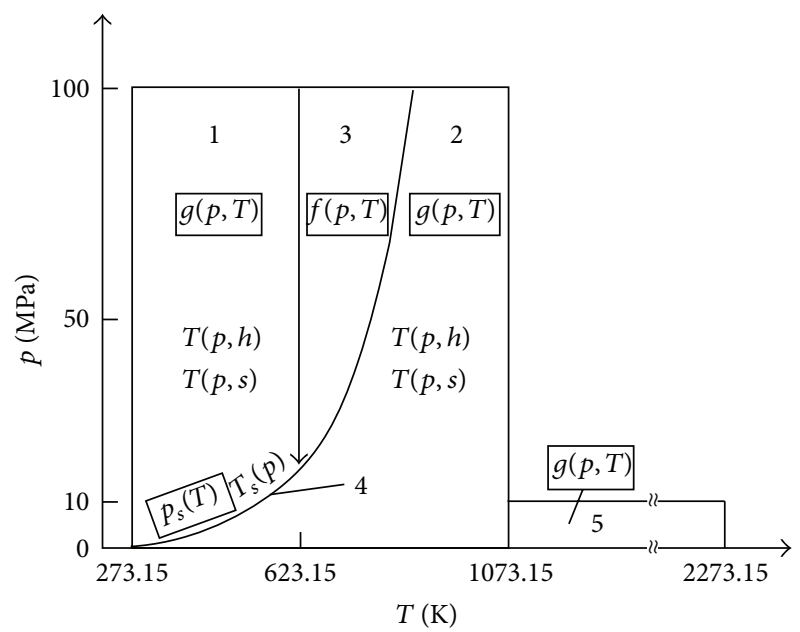

Figure 3: Regions of IAPWS-IF97.

very classic and had been quoted by other scholars [16, 17]; also a quarter of the geometry with symmetry boundary conditions was used. At the nozzle inflow, subsonic flow was specified using total pressure $(25 \mathrm{KPa})$, total temperature (354.6 K), and the outflow is supersonic. With comparison to the IAWPS-IF97 model and the experiment value as Figure 4 shows, it can be seen that IF97 model has a good agreement with the experimental values and is better than ideal gas model. 


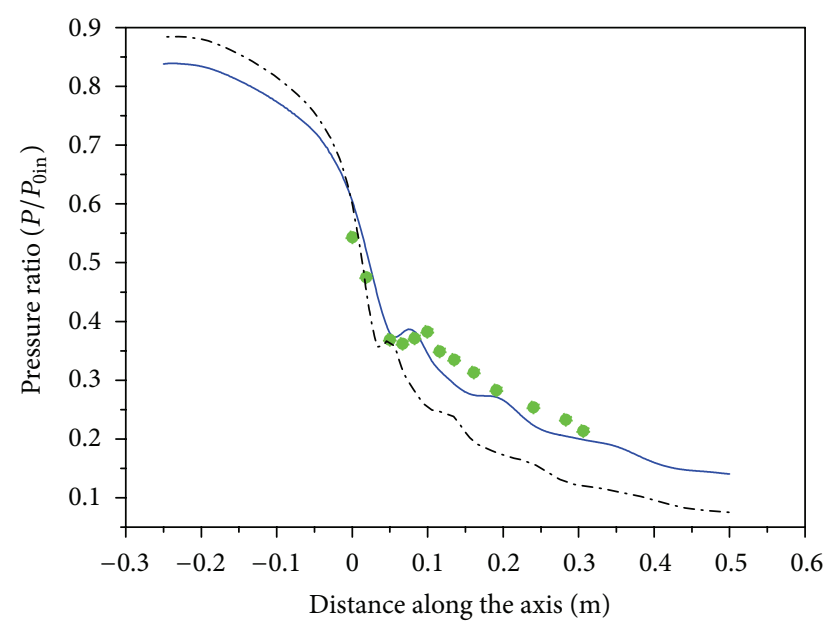

- IAWPS-IF97

- Experiment Moore and Walters [14]

-..- Ideal gas model

FIGURE 4: Pressure distribution of different EOS compared with the Experiments of Moore and Walters [14].

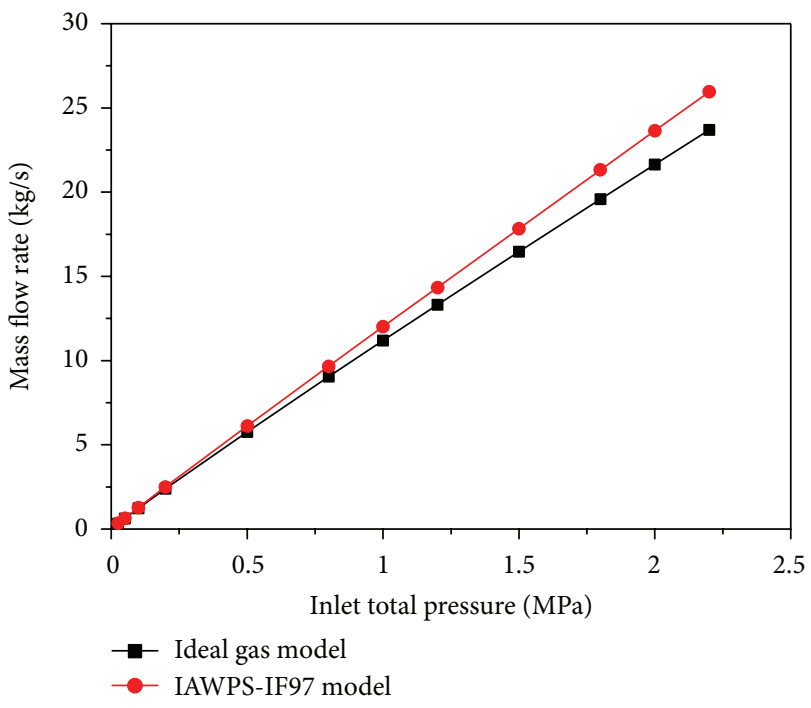

Figure 5: Mass flow rate of nozzle B at different inlet pressure.

4.2. Comparison Results of Different Equations of State. The mass flow rate results of nozzle B at different inlet pressures have been obtained, in order to see how much difference there is between ideal gas model and real gas model. From Figures 5 and 6 it can be seen clearly that when the inlet pressure is lower, for example $0.025 \mathrm{MPa}$, the mass flow rate of real gas model is about $4 \%$ higher than that of ideal gas model, but as the inlet pressure is increased, the difference becomes higher; for example, when inlet pressure is $1.6 \mathrm{MPa}$, the difference is increased to $8.9 \%$, which cannot be ignored.

Figures 7-12 show comparison results of SSE using different EOS. Entrainment ratio is highly underestimated while using ideal gas model, as shown in Figure 7; the entrainment ratio is $40 \%$ lower than real gas model at

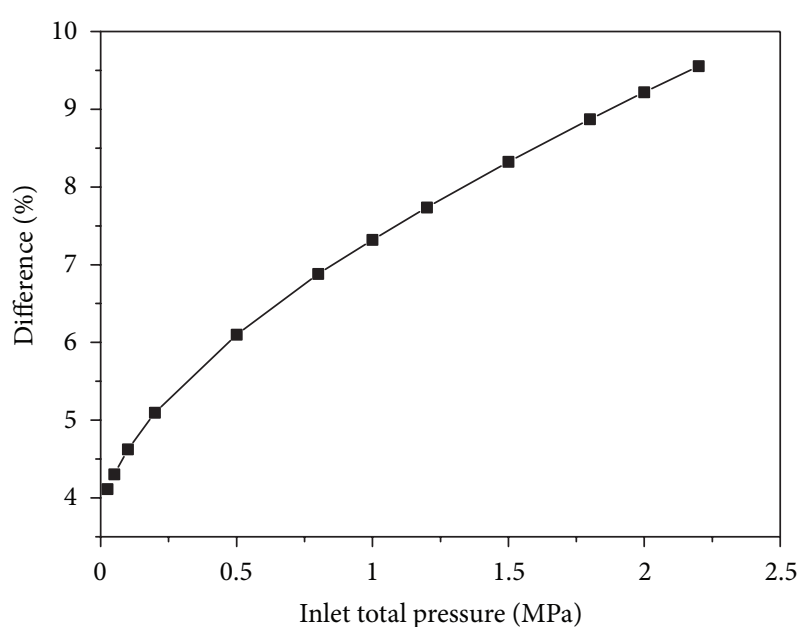

Figure 6: Percent difference of mass flow rate using different EOS.

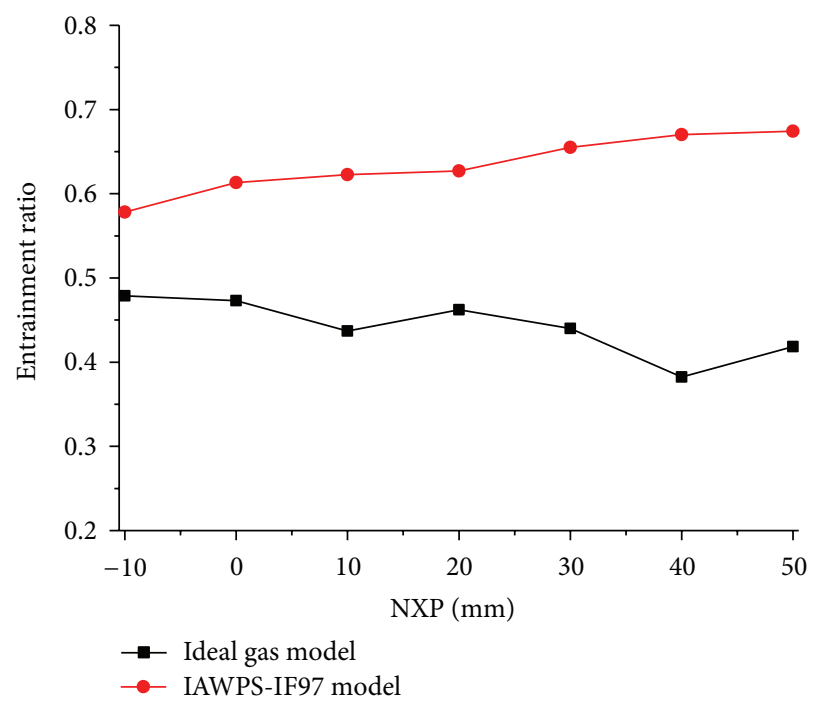

FIGURE 7: Entrainment ratio of the steam ejector at different NXP.

$d=40 \mathrm{~mm}$; this means that when calculating steam ejector flow field, the performance of ejector (entrainment ratio) will be underestimated if using ideal gas model. As Figure 8 shows, the static pressure in mixing chamber is different; when using ideal gas model, static pressure is higher than real gas model.

The working mechanism of the steam ejector could be understood at two aspects: one is viscous drag effect between working and secondary fluid; the other is that with the supersonic expansion of primary fluid, the static pressure in mixing chamber decreases lower than secondary fluid pressure, so the secondary steam will flow into the mixing chamber and will mix with primary fluid (working steam), complete exchange of momentum and energy, so if mixing chamber pressure is higher, the entrainment ratio will be lower; on the other hand, the mass flow rate of ideal gas model is lower than real gas model in a converging-diverging nozzle (Figures 5 and 6); this means that the working fluid 


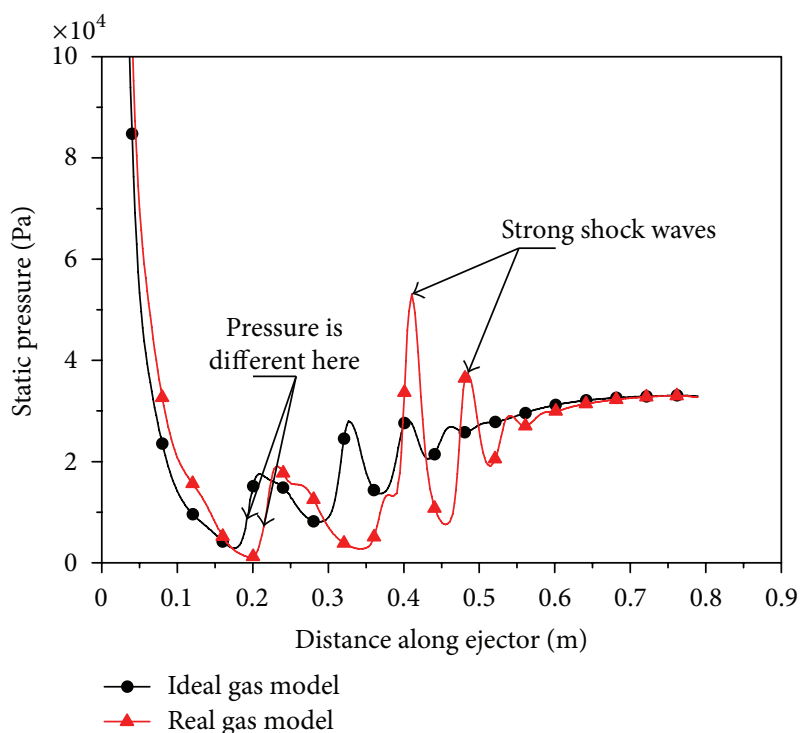

FIGURE 8: Static pressure distribution along the centerline using different EOS.

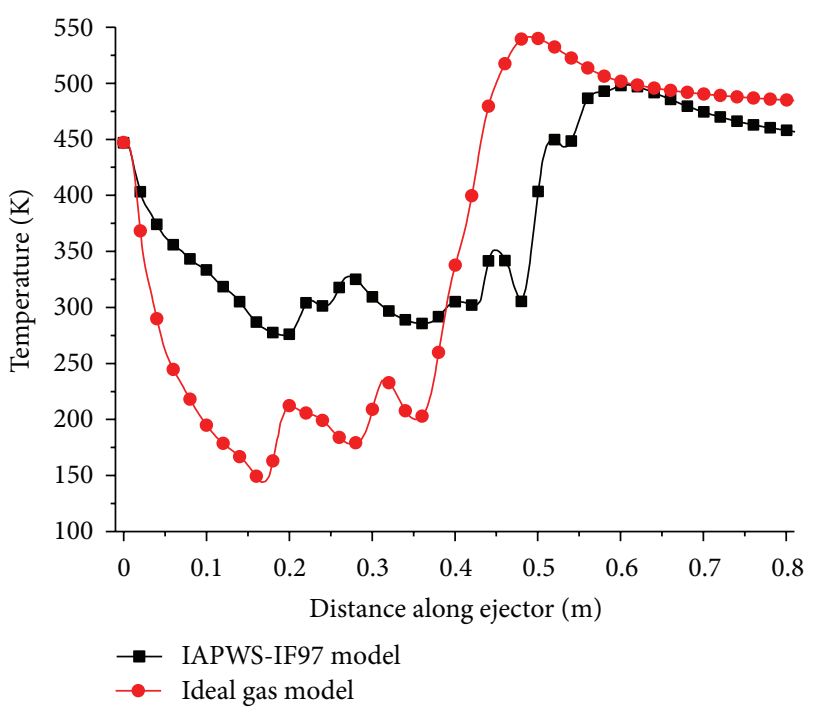

FIGURE 9: Static temperature distribution along the centerline using different EOS.

momentum of ideal gas model is lower, so its dragging ability is poor.

Figure 9 gives the temperature field distribution at middle line; the temperature drops sharply because of the supersonic expansion, and it rises in diffuser. When using ideal gas model the temperature is lower than real gas model; this is because the phase transition phenomenon occurs in the ejector when using the real gas model, the maximum mass fraction of saturated water is larger than 20\% (Figure 10). There are two reasons for phase transition: one is that temperature drops caused by supersonic expansion and shock waves; the other is the secondary fluid's temperature is lower than the primary fluid, latent heat is released when the phase transition phenomenon occur, and the temperature will go

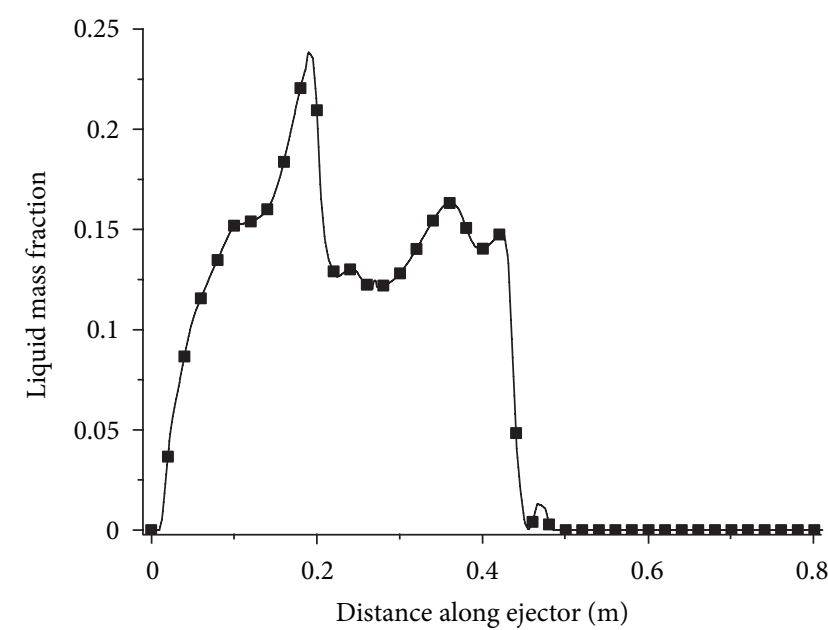

FIGURE 10: Liquid mass fraction distribution along the centerline using IF97.

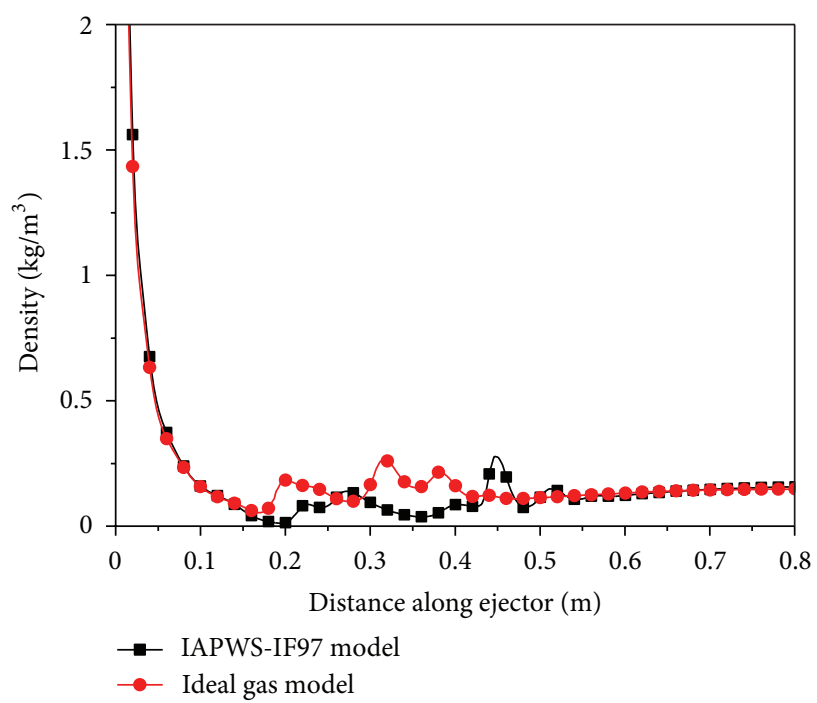

FIGURE 11: Density distribution along the centerline using different EOS.

up. The so-ercalled condensation shock makes the shock waves of real gas model stronger than ideal gas. As the temperature field is underestimated using ideal gas, the mach number and fluid density is also different from IF97 model as Figures 11 and 12 show.

4.3. Geometry Effects on Ejector Entrainment Ratio. As Figure 13 shows, there is an optimum value of $\alpha$ which makes the entrainment ratio be maximum; Figure 14 gives the march number distribution along the axis; if $\alpha$ is smaller than the optimum value, the mixing chamber cannot mix the fluid very well, the choking flow is formed, and a strong shock wave appears in mixing chamber. When $\alpha$ is bigger than optimum value, shock wave attenuation is stronger, and the moment loss in mixing chamber becomes bigger. 


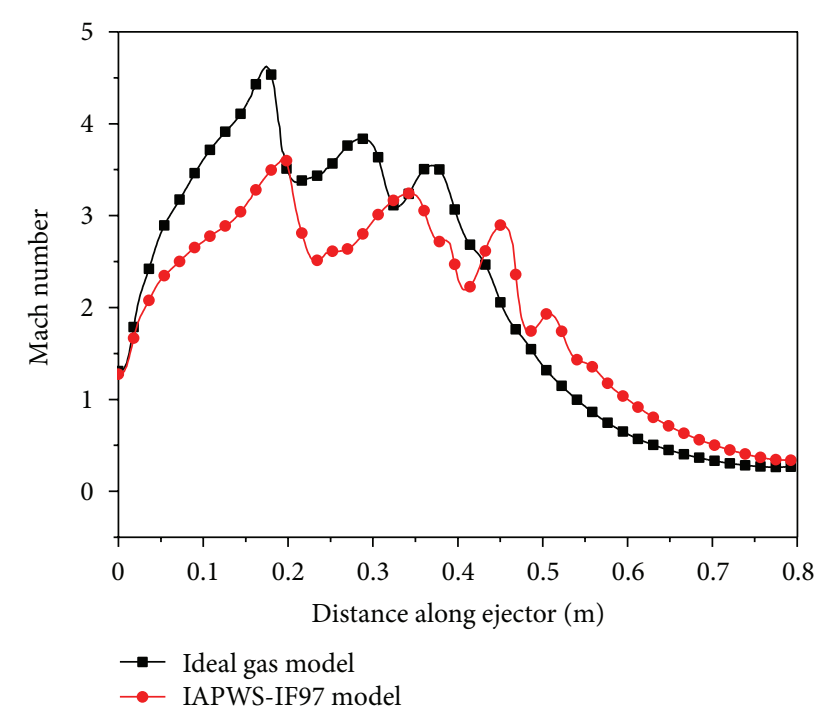

FIGURE 12: Mach number distribution along the centerline using different EOS.

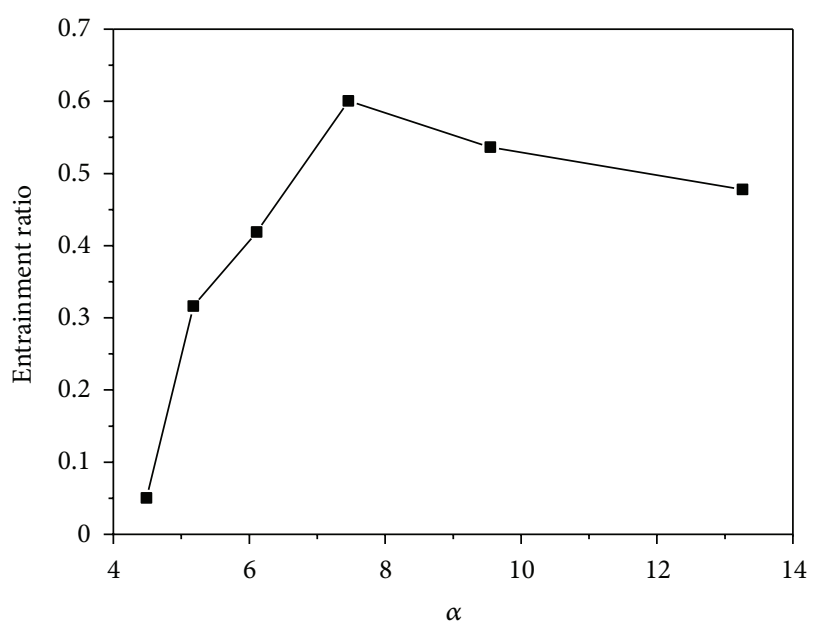

FIgURE 13: Entrainment ratio of the steam ejector at different $\alpha$.

The throat length effects on ejector could be understood as shock waves move toward to mixing chamber when $L$ is decreases. As shown in Figure 15 there are three obvious shock waves when $L=485 \mathrm{~mm}$. The third shock wave has a slight attenuation when $L=385 \mathrm{~mm}$; this is because as $L$ decreases, the high-pressure position in throat exit will move towards mixing chamber; the position of shock wave moves towards mixing chamber; if the choking flow happens in mixing chamber, the entrainment ratio will decrease sharply. For example, the third shock wave in throat disappears when $L=308 \mathrm{~mm}$, and the second shock wave has an apparent attenuation when $L=231$; there is only one shock wave when $L=154 \mathrm{~mm}$. The performance of the ejector is almost unchanged as $L=485 \mathrm{~mm}, 385 \mathrm{~mm}$, and $308 \mathrm{~mm}$, but as $L$ decreases to $231 \mathrm{~mm}, 154 \mathrm{~mm}$, the entrainment ratio decreases as shown in Figure 16; the shock waves will move

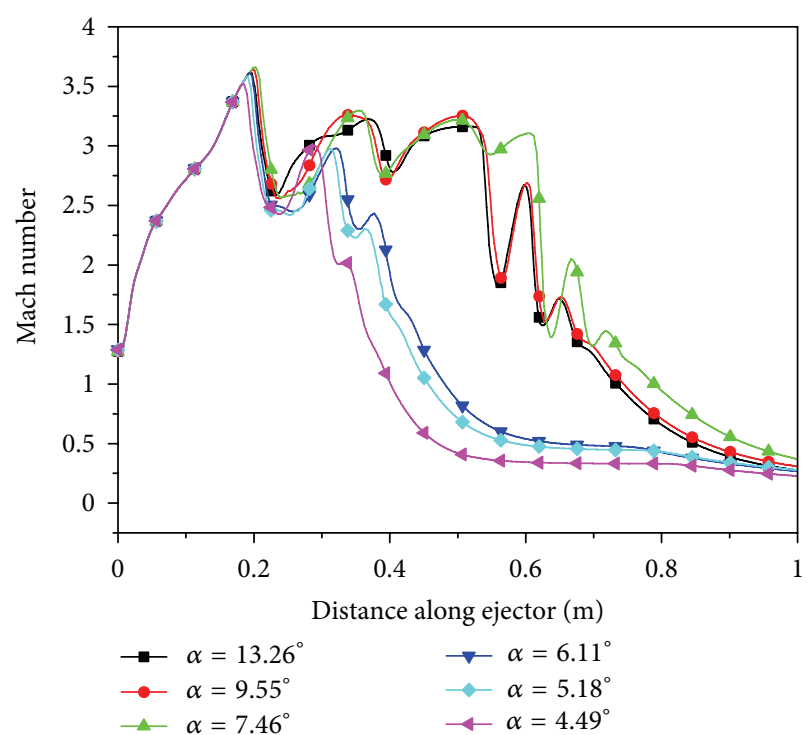

FIGURE 14: Mach distribution along the centerline at different $\alpha$.

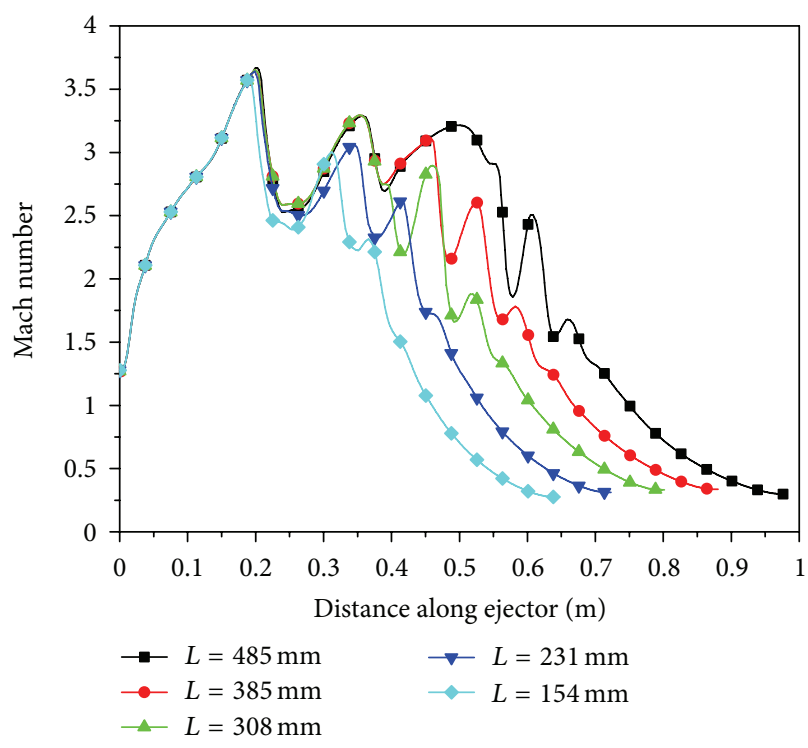

FIGURE 15: Mach distribution along the centerline at different $L$.

towards mixing chamber, leading to static pressure in mixing chamber increased, and make the entrainment decrease.

The primary fluid will be compressed when it is mixed with the second fluid. The distance between primary nozzle and mixing chamber $(d)$ will influence the performance of ejector, but the effects of $d$ on the different ejectors are different. As Figure 4 shows, the optimum value of this ejector is $40 \mathrm{~mm}$, when $d$ is smaller than $40 \mathrm{~mm}$; the maxim pressure in mixing chamber and throat becomes higher, which makes the flow developely inadequate; when $d$ is larger than $40 \mathrm{~mm}$, the speed of fluid reaching mixing chamber droops, and the entrainment ratio decreases a little. It can be seen from Figures 17 and 18 that $d$ does not affect the shock waves distribution in throat and diffuser very much. 


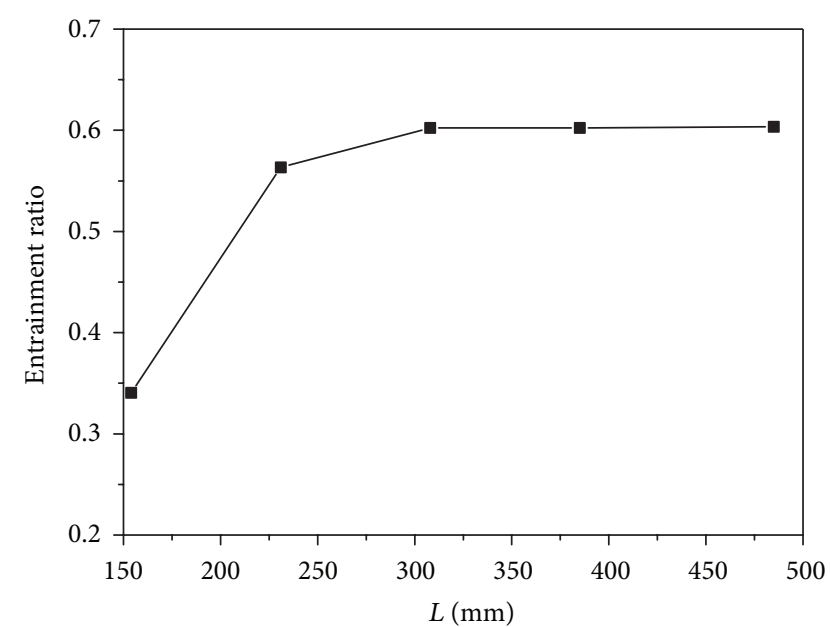

Figure 16: Entrainment ratio of the steam ejector at different $L$.

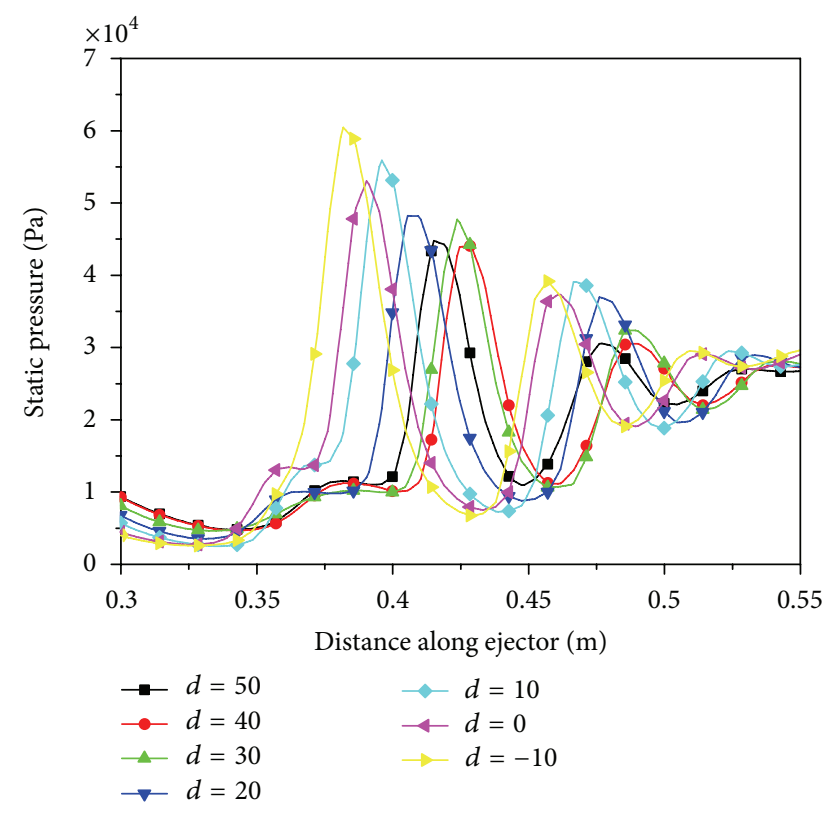

Figure 17: Static pressure distribution along the centerline at different NXP.

\subsection{Working Fluid Condition Effects on Ejector Entrainment} Ratio. In practice, we always want to eject the secondary fluid using lower primary pressure, which makes better energy saving effect and the entrainment be ratio maximum. It can be found in Figure 19 that when the primary pressure is equal to $1.56 \mathrm{MPa}$, the entrainment ratio reaches its maximum value. When $P_{P}$ is higher than $1.56 \mathrm{MPa}$, the choking flow is formed in the mixing chamber area; the block wave will move towards to diffuser when the primary pressure rises as Figure 20 shows. It can be found that when the primary pressure is higher than its critical value, the entrainment is almost unchanged, and the ejector will waste primary steam energy.

The primary fluid often works at saturation state, but this ejector working fluid is superheated; when working

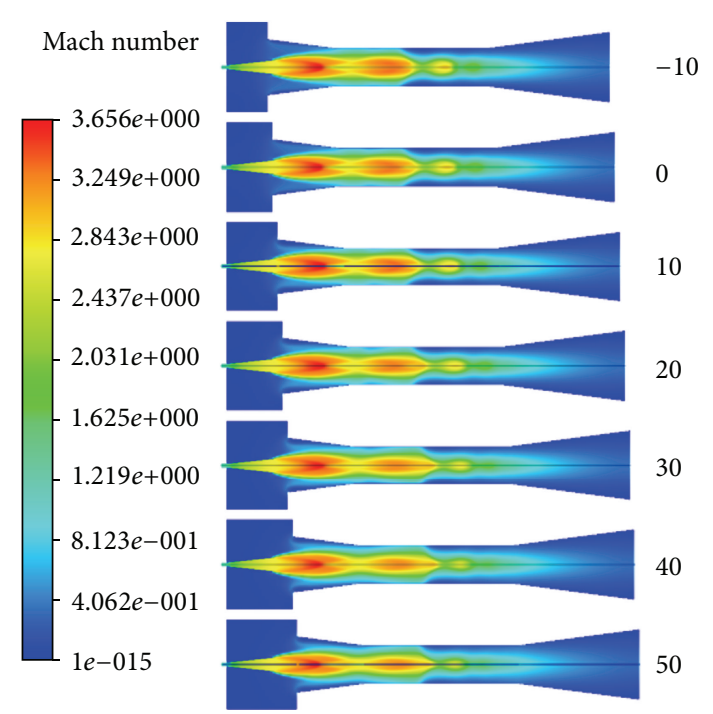

FIGURE 18: Filled contours of mach number at different NXP.

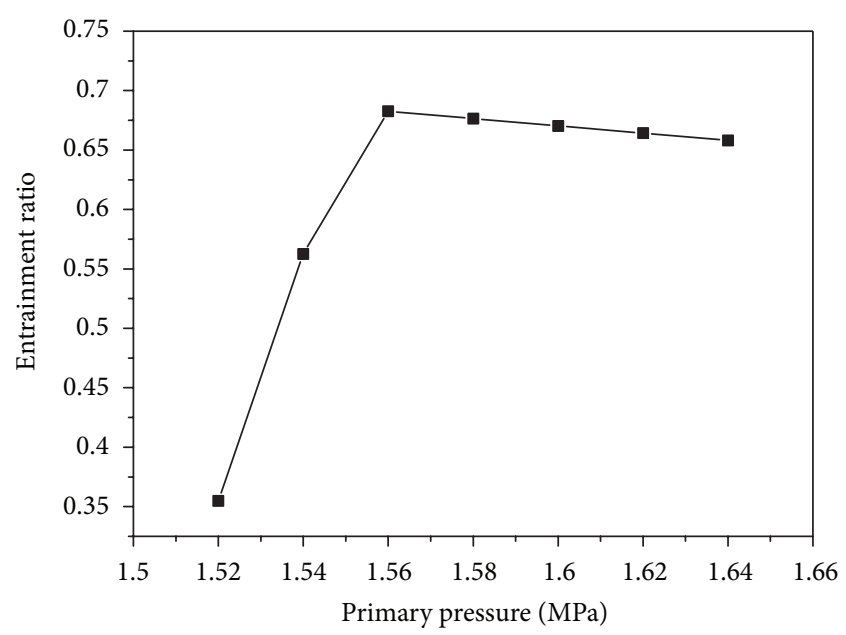

Figure 19: Entrainment ratio of the steam ejector at different $P_{p}$.

steam superheat degree increases, the entrainment ratio is increased; a higher temperature means higher energy and will enhance the ejector performance as Figure 21 shows. The static temperature distribution in mixing chamber and throat is almost the same, but in diffuser it is obvious that a higher primary temperature makes a higher static temperature (Figure 22).

\section{Conclusion}

This paper calculates the flow field of supersonic steam ejector using steam turbine system. The real gas model has been used and compared with ideal gas model first, the water liquid mass fraction in steam ejector has been simulated successfully using IAPWS IF97 real gas model, and the maximum mass fraction of saturated water is higher than $20 \%$. Mixing chamber angel, throat length, and nozzle exist 


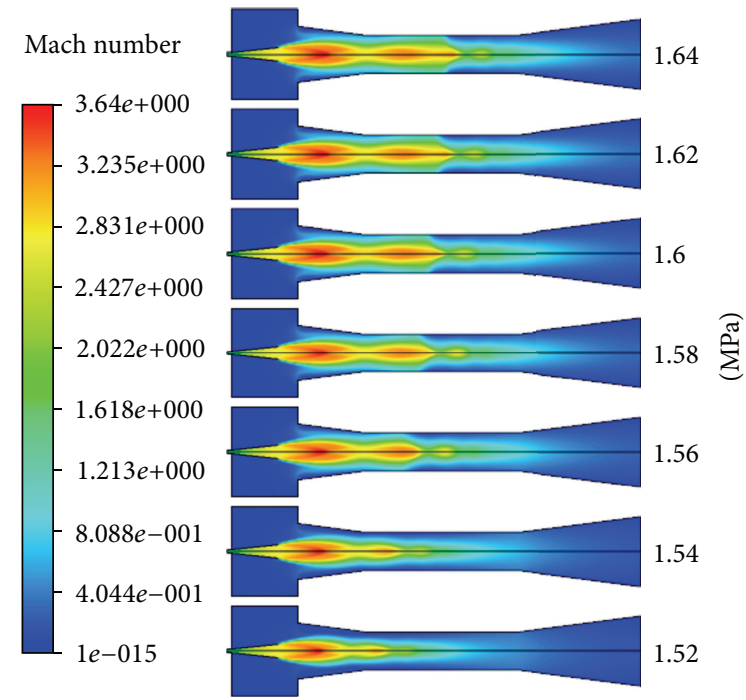

Figure 20: Filled contours of mach number at different $P_{p}$.

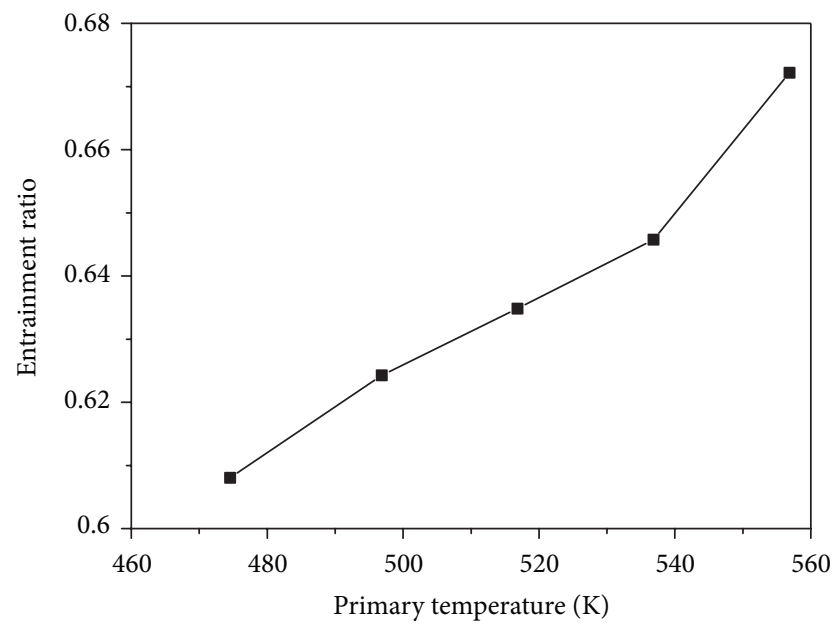

Figure 21: Entrainment ratio of the steam ejector at different $P_{p}$.

position effects on ejector performance have been discussed. The other conclusions are summarized as follows.

(1) The verification calculation result of convergingdiverging nozzle shows that if the inlet pressure is higher, the ideal gas model is no longer fit for steam flow problems.

(2) The mass flow rate and static pressure are the main causes of difference between two equations of state; for the ejector in this paper, the performance of the ejector will be underestimated and the temperature field is distorted using ideal gas model; the entrainment ratio of ideal gas is maximum $40 \%$ lower than IF97 model.

(3) There are an optimum mixing chamber angle and NXP makes the entrainment ratio achieves its maximum. As throat length decreased within a range (3D length in this paper), the entrainment ratio remains

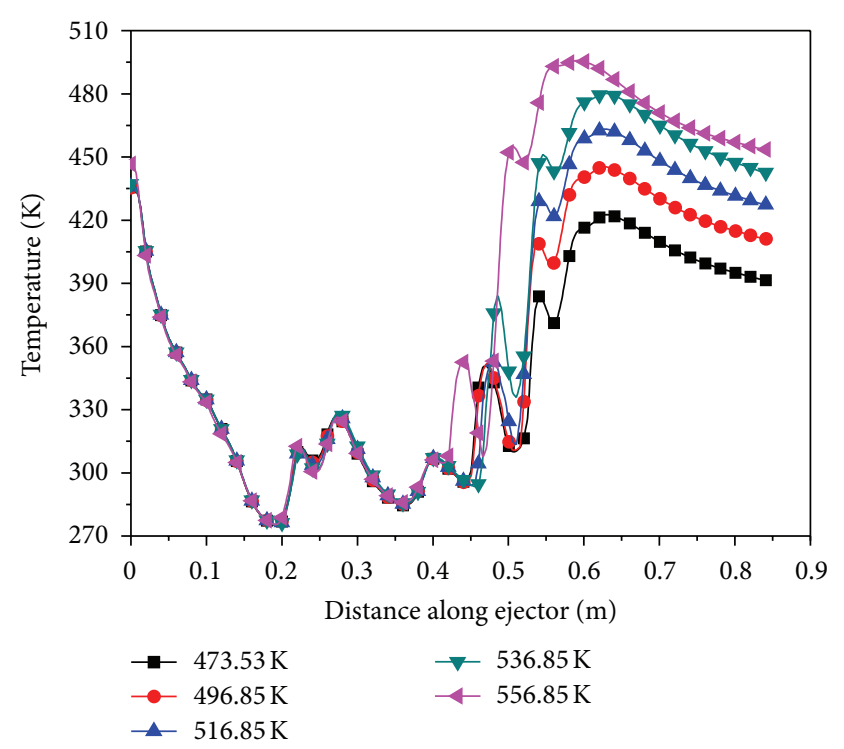

FIgURE 22: Filled contours of mach number at different $P_{p}$.

unchanged. The influence mechanism to entrainment ratio could be understood as choking flow exists in mixing chamber, and if chocking flow happens in mixing chamber, the performance of ejector will be reduced.

(4) The primary pressure has a critical value at a certain primary temperature; when it is higher than critical value, the entrainment ratio decreases a little. The entrainment ratio increases as the superheat degree of primary steam increases.

\section{References}

[1] S. Akterian, "Improving the energy efficiency of traditional multi-stage steam-jet-ejector vacuum systems for deodorizing edible oils.", Procedia Food Science, vol. 1, pp. 1785-11791, 2011.

[2] M. L. Ferrari, D. Bernardi, and A. F. Massardo, "Design and testing of ejectors for high temperature fuel cell hybrid systems," Journal of Fuel Cell Science and Technology, vol. 3, no. 3, pp. 284291, 2006.

[3] K. Zhang and F. Xue, "Experiment study and guidelines of highpressure gas ejector," Journal of Thermal Science and Technology, vol. 3, pp. 133-138, 2004.

[4] D. W. Sun and I. W. Eames, "Recent developments in the design theories and applications of ejectors-a review," Journal of the Institute of Energy, vol. 68, no. 475, pp. 65-79, 1995.

[5] I. W. Eames, S. Aphornratana, and H. Haider, "A theoretical and experimental study of a small-scale steam jet refrigerator," International Journal of Refrigeration, vol. 18, no. 6, pp. 378-386, 1995.

[6] B. J. Huang, J. M. Chang, C. P. Wang, and V. A. Petrenko, "A 1-D analysis of ejector performance," International Journal of Refrigeration, vol. 22, no. 5, pp. 354-364, 1999.

[7] M. Ouzzane and Z. Aidoun, "Model development and numerical procedure for detailed ejector analysis and design," Applied Thermal Engineering, vol. 23, no. 18, pp. 2337-2351, 2003. 
[8] Y. Bartosiewicz, Z. Aidoun, P. Desevaux, and Y. Mercadier, "Numerical and experimental investigations on supersonic ejectors," International Journal of Heat and Fluid Flow, vol. 26, no. 1, pp. 56-70, 2005.

[9] E. Rusly, L. Aye, W. W. S. Charters, and A. Ooi, "CFD analysis of ejector in a combined ejector cooling system," International Journal of Refrigeration, vol. 28, no. 7, pp. 1092-1101, 2005.

[10] S. Pietrowicz and J. Kasperski, "The Thermo-flow processes proceeding during the two-phase flow in supersonic ejector applied in low power solar air conditioning Systems," in Proceedings of the International Congress of Refrigeration, Beijing, China, 2007, ICR07-E1-1073.

[11] T. Sriveerakul, S. Aphornratana, and K. Chunnanond, "Performance prediction of steam ejector using computational fluid dynamics: part 1. Validation of the CFD results," International Journal of Thermal Sciences, vol. 46, no. 8, pp. 812-822, 2007.

[12] K. Pianthong, W. Seehanam, M. Behnia, T. Sriveerakul, and S. Aphornratana, "Investigation and improvement of ejector refrigeration system using computational fluid dynamics technique," Energy Conversion and Management, vol. 48, no. 9, pp. 2556-2564, 2007.

[13] D. Scott, Z. Aidoun, O. Bellache, and M. Ouzzane, "CFD simulations of a supersonic ejector for use in refrigeration applications," in Proceedings of the International Refrigeration and Air Conditioning Conference at Purdue, July 2008, paper 927.

[14] M. J. Moore and P. T. Walters, "Predicting the fog drop size in wet steam turbines," in Proceedings of the Wet Steam 4 Conference, Institute of Mechanical Engineers (UK), University of Warwick, 1973, paper C37/73.

[15] W. Wagner, J. R. Cooper, A. Dittmann et al., "The IAPWS industrial formulation 1997 for the thermodynamic properties of water and steam," Journal of Engineering for Gas Turbines and Power, vol. 122, no. 1, pp. 150-180, 2000.

[16] Y. Yang and S. Shen, "Numerical simulation on non-equilibrium spontaneous condensation in supersonic steam flow," International Communications in Heat and Mass Transfer, vol. 36, no. 9, pp. 902-907, 2009.

[17] M. J. Kermani and A. G. Gerber, "A general formula for the evaluation of thermodynamic and aerodynamic losses in nucleating steam flow," International Journal of Heat and Mass Transfer, vol. 46, no. 17, pp. 3265-3278, 2003. 


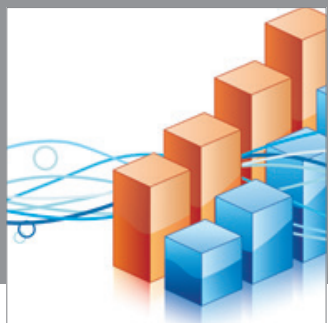

Advances in

Operations Research

mansans

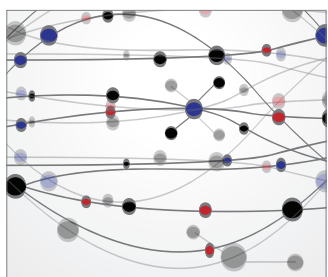

The Scientific World Journal
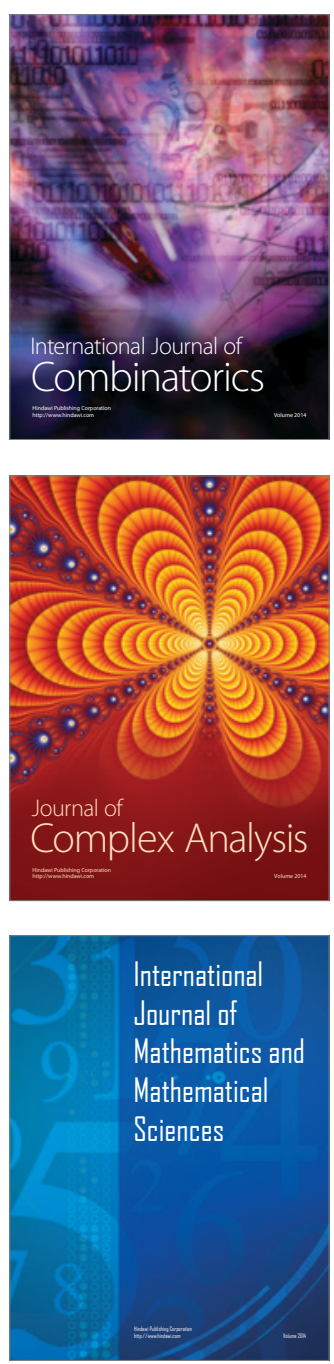
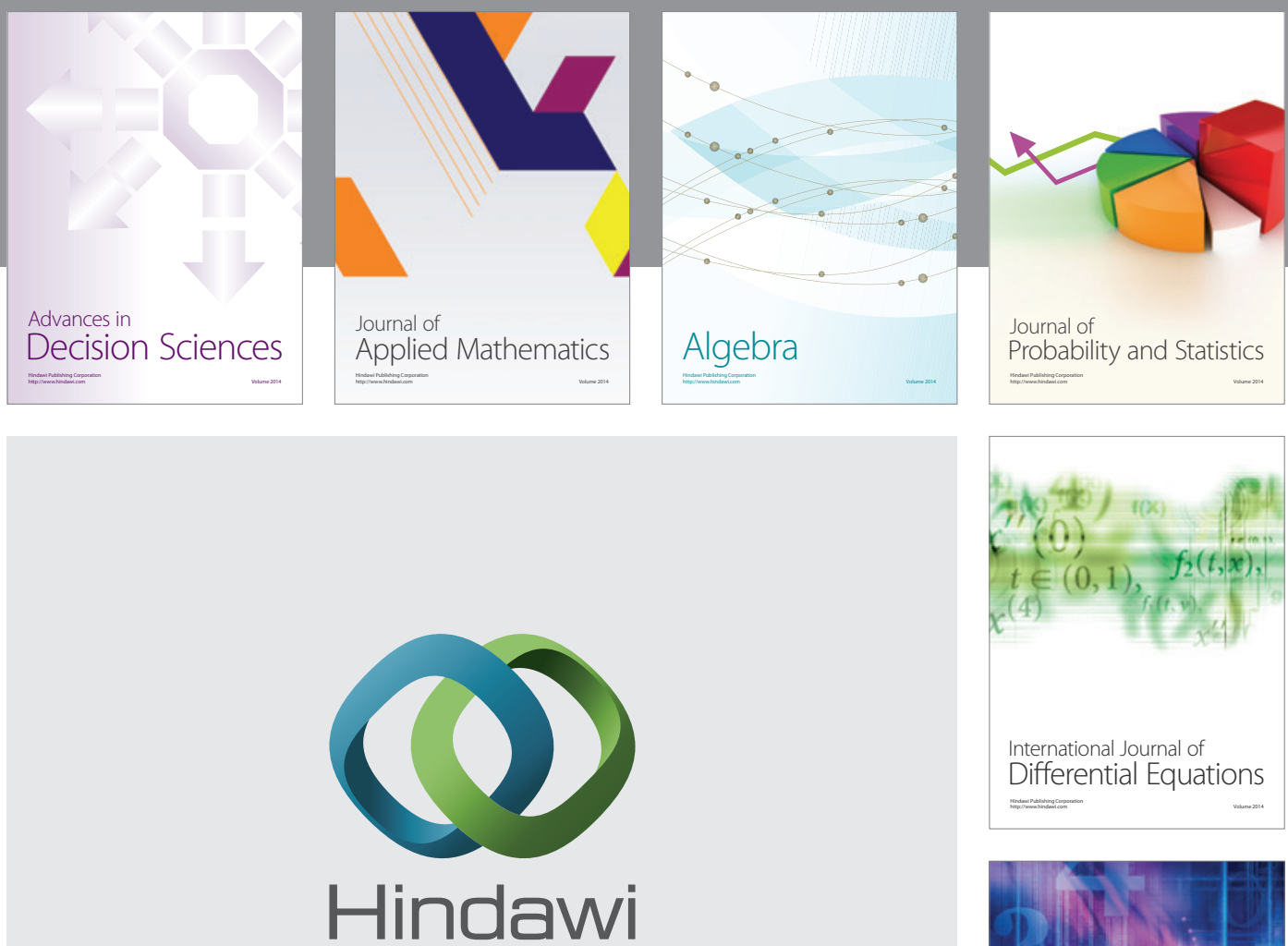

Submit your manuscripts at http://www.hindawi.com
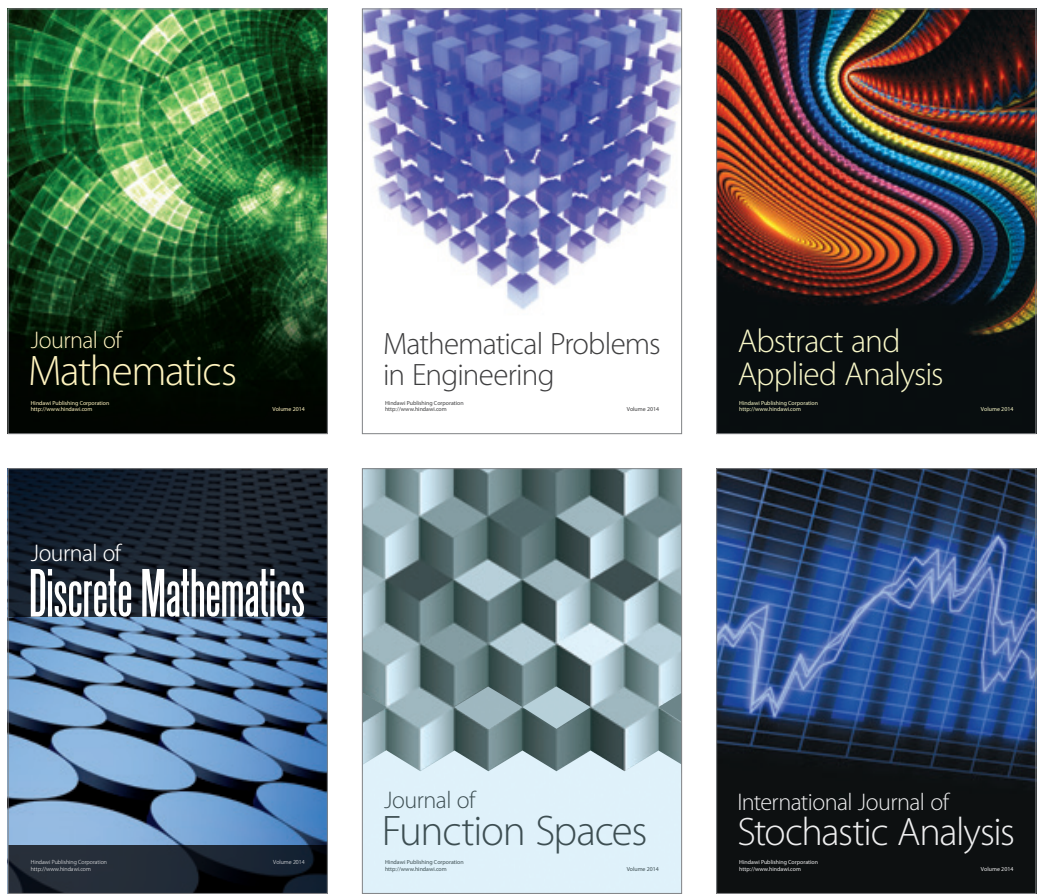

Journal of

Function Spaces

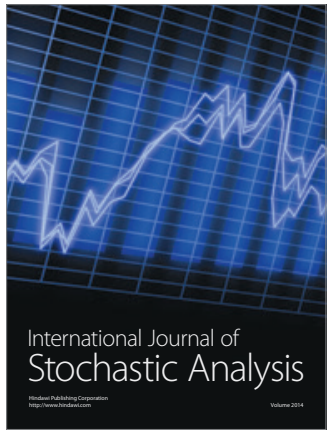

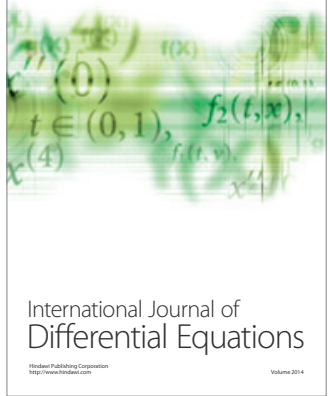
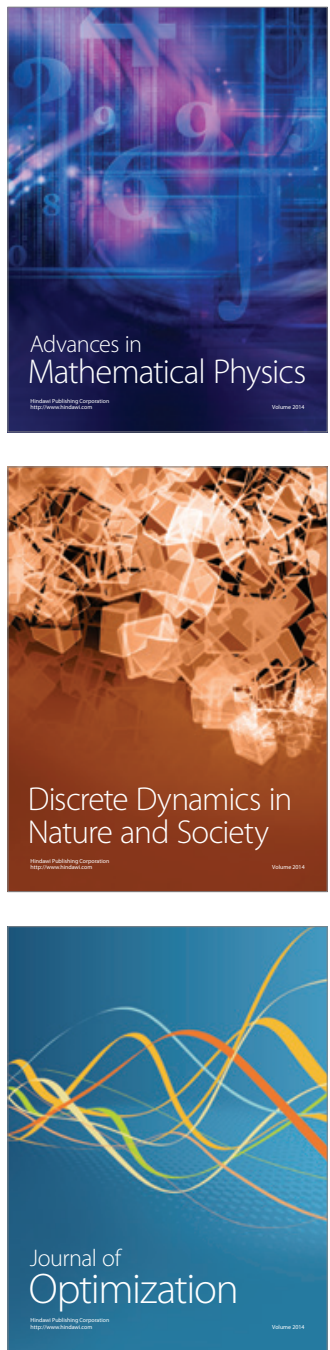